\title{
The Genetics and Biochemistry of Mutants of Aspergillus nidulans Resistant to Chlorinated Nitrobenzenes
}

\author{
By R. J. THRELFALL \\ Department of Botany, Imperial College, London, S.W.7 \\ (Accepted for publication 15 November 1967)
}

SUMMARY

\begin{abstract}
2,3,5,6-Tetrachloronitrobenzene (TCNB) was a more effective fungistat than pentachloronitrobenzene (PCNB) for Aspergillus nidulans. Four mutants selected for resistance to TCNB or PCNB were resistant to both these compounds and to other halogenated nitrobenzenes, diphenyl, methylene blue and brilliant cresyl green. Resistance was conferred by either of two recessive genes in linkage group III. Three of the mutants were allelic. In crosses the frequency of resistant ascospores was less than $50 \%$. Diploids heterozygous for resistance exposed to PCNB produced fast-growing resistant haploid or homozygous diploid segregants. PCNB decreased growth more than DNA synthesis in sensitive strains but these were unaffected in resistant strains. Five times as much TCNB was extracted from the mycelium of sensitive strains than from that of resistant strains. Resistance is probably caused by an inability to take up the chemicals rather than to an ability to metabolize them.
\end{abstract}

\section{INTRODUCTION}

When a chemical compound is used to control or prevent the growth of a microorganism strains resistant to the compound may subsequently appear. How the compound acts on the organism and how this action is avoided or overcome by the resistant strain has considerable biochemical and genetical interest. Pentachloronitrobenzene (PCNB) and 2,3,5,6-tetrachloronitrobenzene (TCNB) are widely used for the control of diseases caused by Rhizoctonia solani and Botrytis cinerea (Brown \& Montgomery, 1948). Strains of the imperfect fungi B. allii (Priest \& Wood, I96I) and Fusarium caeruleum (McKee, 195I) resistant to chlorinated nitrobenzenes have been described, but not analysed genetically. In Hypomyces solani f. cucurbitae any one of three loci can mutate to give resistance to PCNB and TCNB (Georgopoulos, 1963). In Aspergillus nidulans, strains resistant to acriflavine (Roper \& Käfer, 1957), fluoroacetate (Apirion, 1962) and $p$-fluorophenylalanine, teoquil, iodoacetate, actidione and malachite green (Warr \& Roper, 1965) have been described and analysed genetically. No reports have appeared on strains of $A$. nidulans resistant to fungicides used in agriculture. This is perhaps not surprising, because the fungus is not a pathogen. The ease with which genetic analysis can be done with $A$. nidulans was the reason for its use in this study of the nature of its resistance to PCNB and TCNB.

\section{METHODS}

The general and genetic techniques used in this work were those of Pontecorvo et al. (1953). Incubation was at $37^{\circ}$. 
Organisms. Mutant stocks of Aspergillus nidulans were obtained from Dr B. W. Bainbridge (Department of Microbiology, Queen Elizabeth College, Campden Hill Road, London, W.8), the Department of Genetics University of Glasgow, or the Fungal Genetics Stock Center, Department of Biological Sciences, Dartmouth College, Hanover, New Hampshire, U.S.A. The mutants used in this work were $y$, yellow conidia; $w 2$, white conidia; $a d 20, \arg 2, b i \mathrm{I}, l y s 5$, meth 2 , nic 8 , phen 2, pro I, pyro 4 , ribo 2, $s 3$ growth requirements, respectively, for adenine, arginine, biotin, lysine, methionine, nicotinic acid, phenylalanine, proline, pyridoxine, riboflavin and sulphite; gal I, unable to grow with galactose as sole carbon source; Acr I, resistance to acriflavine and $s u \mathrm{I} a d 20$, suppressor of $a d 20$. Details of these mutant alleles are given in Pontecorvo et al. (1953), Roper \& Käfer (1957), Käfer (1958) and Roberts (I963). These stocks were maintained on complete medium. Where necessary these stocks and others obtained during the work were purified by the isolation of a single conidium with a de Fonbrune micromanipulator.

Media. Minimal medium (MM): $\mathrm{NaNO}_{3}, 6 \cdot 0$ g.; $\mathrm{MgSO}_{4} 7 \mathrm{H}_{2} \mathrm{O}, 0.52 \mathrm{~g}$; $\mathrm{KCl}, 0.52 \mathrm{~g}$; $\mathrm{KH}_{2} \mathrm{PO}_{4}, \mathrm{I} \cdot 52 \mathrm{~g}$.; glucose, I0.0 g.; trace $\mathrm{FeSO}_{4}$ and $\mathrm{ZnSO}_{4}$; distilled water to I 1.; adjusted to $\mathrm{pH} 6.5$ with $5 \%(\mathrm{w} / \mathrm{v}) \mathrm{NaOH}$. Complete medium (CM): yeast extract (Difco), I॰o g.; peptone (Difco), I॰ g.; Casamino acids (Difco, certified), I॰o g.; glucose, I0.0 g.; vitamin solution, I ml. (biotin, $0.01 \mathrm{~g}$; thiamine $\mathrm{HCl}, 0.0 \mathrm{I}$ g.; riboflavin, o.oI g.; $p$-aminobenzoic acid, 0.0I g.; nicotinic acid, o.or g.; pyridoxin $\mathrm{HCl}, 0.0$ I g.; water to $100 \mathrm{ml}$.); distilled water to I $1 ., \mathrm{pH} 6 \cdot 0$. For the growth of adenine auxotrophs media were supplemented with 0.15g. adenine/1. CM was deficient in arginine, methionine, phenylalanine and riboflavine so that these were added to the media when required by mutant stocks. Media were solidified by the addition of $15 \mathrm{~g}$. Oxoid Ionagar no. 2/1. Cultures grown in liquid media were set up in $250 \mathrm{ml}$. Oxoid flasks containing $50 \mathrm{ml}$. medium. The components of liquid MM were autoclaved separately, mixed, the $\mathrm{pH}$ adjusted with $5 \%(\mathrm{w} / \mathrm{v}) \mathrm{NaOH}$ and dispensed into sterile flasks. Liquid CM was prepared in bulk, distributed and sterilized in the flasks.

Chemicals. The five fungicides used were pentachloronitrobenzene (PCNB), 2,3,5,6tetrachloronitrobenzene (TCNB) and 2,5-dibromonitrobenzene (DBNB) recrystallized from ethanol and I,3-diffuoro-7,6-dinitrobenzene (DFDNB) recrystallized from acetic acid. Other chemicals were of Analar grade where available. Stains were obtained from G. T. Gurr (136/177, New Kings Road, London, S.W.6). Purified calf thymus DNA, glucose oxidase and peroxidase were purchased from Seravac Laboratories, Maidenhead, Berkshire.

Analysis of cultures grown in liquid media. The fungal mycelium was collected by filtration through Whatman no. 57I filter paper and when necessary a sample of the filtrate was stored at $-20^{\circ}$ for analysis later. The mycelium was washed with water, twice with $25 \mathrm{ml}$. industrial methylated spirit ( 74 o.p.), then with $25 \mathrm{ml}$. acetone, squeezed between blotting paper, removed from the paper, dried on a glazed tile at $55^{-60^{\circ}}$ for at least $4 \mathrm{hr}$ and then weighed. DNA was measured as follows. Not more than $100 \mathrm{mg}$. dry mycelium was extracted twice with $2.5 \mathrm{ml}$. and then with $5.0 \mathrm{ml}$. ethanol +chloroform mixture $(3+\mathrm{I}, \mathrm{v} / \mathrm{v})$ for periods of $20 \mathrm{~min}$. at $75^{\circ}$. It was then extracted with $2.5 \mathrm{ml} .6 \%(\mathrm{v} / \mathrm{v})$ perchloric acid for $20 \mathrm{~min}$. at $70^{\circ}$. To $2.0 \mathrm{ml}$. of the perchloric acid extract was added $4.0 \mathrm{ml}$. diphenylamine reagent (Burton, 1956), incubated overnight at $37^{\circ}$ and the extinction read at $600 \mathrm{~m} \mu$. A sample of calf thymus 
DNA was hydrolysed and standards prepared at the same time. Culture filtrates were analysed for phosphate by the method of Fiske \& SubbaRow (1925), for glucose with a glucose oxidase reagent in $0.5 \mathrm{M}$-tris at $\mathrm{pH} 7.0$ (Dahlqvist, I96I) and for amino acids by the method of Moore \& Stein (1948) with leucine as standard.

Analysis of 2,3,5,6-tetrachloronitrobenzene. A modification of the method of Auerbach (1950) was used. One-half $\mathrm{ml}$. of a $25 \%$ (v/v) solution of tetra-ethylammonium hydroxide (British Drugs Houses Ltd., Poole, Dorset) was diluted with $12.5 \mathrm{ml}$. absolute ethanol. To $0 . \mathrm{I} \mathrm{ml}$. of this was added $4.9 \mathrm{ml}$. acetone extract containing o-60 $\mu \mathrm{g}$. TCNB and the extinction read at $550 \mathrm{~m} \mu$ between 4 and $7 \mathrm{~min}$. after mixing.

Cytological technique. Strips of thin sterile Cellophane $(2 \times \mathrm{I}$ in. $)$ were placed on the surface of CM agar in Petri dishes and inoculated with a suspension of conidia. After incubation the strips were removed, fixed in Helly's fluid for $10 \mathrm{~min}$., washed in $70 \%(\mathrm{v} / \mathrm{v})$ ethanol in water, hydrolysed with $\mathrm{N}$-hydrochloric acid at $60^{\circ}$ for $10 \mathrm{~min}$. and stained in diluted Giesma for $3 \mathrm{hr}$ (Giesma R $66 \mathrm{I} \cdot 5 \mathrm{ml}$.; M/I 5 phosphate buffer, $\mathrm{pH} 6.9,30 \mathrm{ml}$.). The material was differentiated by washing the strips for about $75 \mathrm{sec}$. in distilled water containing a trace of acetic acid. The strips were mounted for examination in dilute stain (Giesma R 66, 7 drops; $\mathrm{M} / \mathrm{I} 5$ phosphate buffer, $\mathrm{pH} 6.9$, $20 \mathrm{ml}$.).

\section{RESULTS}

Effect of $P C N B$ and TCNB on growth and morphology of wild type

A series of Petri dishes $(8.5 \mathrm{~cm}$. diameter) of $\mathrm{CM}$ agar containing known amounts of PCNB (0-0.5 mg./ml.) were prepared by adding PCNB dissolved in acetone to the warm medium before the plates were poured. The plates were inoculated with about 200 conidia/plate. After incubation for 3 days the colonies were counted. On plates containing more than $0.05 \mathrm{mg}$. $\mathrm{PCNB} / \mathrm{ml}$. the colonies did not exceed $2 \mathrm{~mm}$. in diameter. There was no significant difference $(P=0.0 \mathrm{I})$ between the control and PCNB plates. A similar experiment was made with $0.0 \mathrm{I}-10.0 \mathrm{mg}$. PCNB deposited in the lids of a series of dishes from acetone solutions. Again the viability of conidia was unchanged.

The effect of PCNB on growth was examined by inoculating a series of plates at the centre with a $2 \mathrm{~mm}$. disc of mycelium cut with a cork borer from the periphery of a colony growing on $\mathrm{CM}$ agar. The average diameter of the colonies after 6 days is shown in Fig. I. At $0.005 \mathrm{mg}$. PCNB/ml. growth was decreased, while at $0.05 \mathrm{mg}$. 1 $\mathrm{ml}$. the colonies were only about one-sixteenth the area of control colonies. Increasing the concentration above $0.05 \mathrm{mg}$. $/ \mathrm{ml}$. did not lead to greater inhibition. At concentrations above $0.0 \mathrm{I} \mathrm{mg} . / \mathrm{ml}$. conidiation was progressively decreased and was almost absent at $0.05 \mathrm{mg} . / \mathrm{ml}$.

TCNB also decreased growth and conidiation; above $0.05 \mathrm{mg} . / \mathrm{ml}$. there was no conidiation and the colonies were bright pink. At $0.1 \mathrm{mg} . / \mathrm{ml}$. inhibition was complete but the organisms were not dead because growth started again on transfer of the inoculum to medium without TCNB. Thus PCNB and TCNB were fungistatic rather than fungicidal.

\section{Isolation of $P C N B$ - and TCNB-resistant strains}

At any time during exposure to PCNB fan-shaped fast-growing sectors developed. Ten sectors taken at random, each from different colonies of the wild type growing on CM agar and exposed to the vapour from $\mathrm{I} \cdot 0 \mathrm{mg}$. PCNB in the lid of the dish, 
were examined in detail. They were found to differ from each other in several ways. Three of the sectors grew poorly on CM agar, produced an excess of aerial hyphae with few conidiophores and the edge of the colony was indented. Looked at through the bottom of the dish these strains were dark brown. When grown on CM agar containing $0.2 \mathrm{mg}$. PCNB $/ \mathrm{ml}$. these strains were normal in every way. Three other sectors had normal morphology in the absence of PCNB but produced excessive aerial hyphae in its presence. Another three sectors appeared to be normal whether PCNB was present or not; one of these sectors had a growth rate similar to that of the wild-type parent but the other two grew slowly. The tenth sector lost its resistance to PCNB on subculture while the others retained their resistance through several transfers by using conidia or mycelium. None of the resistant strains derived from the wild-type parent had any nutritional requirement.

\section{Table I. Strains of Aspergillus nidulans resistant to pentachloronitrobenzene} $(P C N B)$ and tetrachloronitrobenzene $(T C N B)$

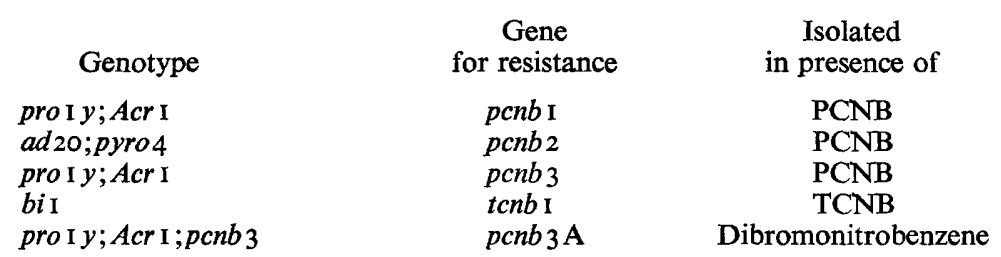

Plates of $\mathrm{CM}$ agar containing $0.2 \mathrm{mg}$. $\mathrm{PCNB} / \mathrm{ml}$. were inoculated with mutant auxotrophic strains of Aspergillus nidulans. After incubation one resistant sector was picked. Repeated attempts to isolate a resistant strain in the presence of TCNB were unsuccessful. This may have been because so little growth was made that the probability of a mutation to resistance taking place among so few nuclei was slight. Therefore plates of CM agar were inoculated and $10 \mathrm{mg}$. TCNB added to the lid after 2 days. After further incubation a few tolerant sectors developed but their frequency was much less than that of sectors developing in the presence of PCNB. One sector resistant to TCNB and three resistant to PCNB have been studied. The genotypes of the parental strains are shown in Table I, where resistance has been tentatively ascribed to four genes. On $\mathrm{CM}$ agar in the presence of dibromononitrobenzene the original pro I $y ; A c r$ I; $p c n b 3$ strain produced a fast-growing sector which still carried $p c n b_{3}$. The strain grown from this sector was called $p c n b_{3} \mathrm{~A}$; a second mutation may have occurred, either at the pcnb 3 locus or elsewhere, but this was not investigated.

\section{Response of resistant strains to other inhibitors}

The effect of several chemicals on the growth of the isolates of Table I and of prototrophic-resistant recombinants obtained from crosses (see Table 2) was measured by the average of two diameters at right angles of colonies incubated for 6 days on $\mathrm{CM}$ agar containing the chemical. The source of inoculum, whether taken from cultures grown with or without PCNB (or TCNB) had no effect on the final size of the colony. Figure I shows that the strain having the greatest resistance to PCNB was that isolated in the presence of TCNB. In the absence of PCNB strains $p c n b_{I}$ and $p c n b 2$ grew much less than the other strains; $p c n b 2$ was stimulated by PCNB. At high 
concentrations of PCNB growth of $p c n b \mathrm{I}$ was decreased more than that of $p c n b 2$ or $p c n b 3$. These properties were shown on MM agar but the differences between strains was less marked. Figure 2 shows that the strain selected in the presence of TCNB was no more resistant to it than were those selected in the presence of PCNB. At more than $0.05 \mathrm{mg}$. TCNB $/ \mathrm{ml}$. growth of all resistant strains was suppressed and all became pink in colour. Strains carrying $p c n b$ I or $p c n b 2$ were found to be resistant to dichloronitrobenzene and dibromonitrobenzene at concentrations up to $0 . \mathrm{I} \mathrm{mg} . / \mathrm{ml}$. All strains were completely inhibited by difluorodinitrobenzene at $0.01 \mathrm{mg} . / \mathrm{ml}$. and by dinitrophenol at $0.05 \mathrm{mg} . / \mathrm{ml}$. Priest \& Wood (196I) found that strains of Botrytis

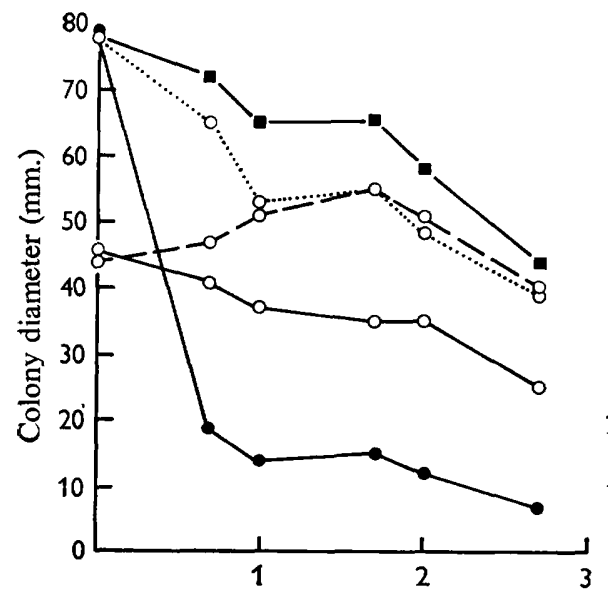

$\log _{10} \mu \mathrm{g}$. PCNB/ml. medium

Fig. I

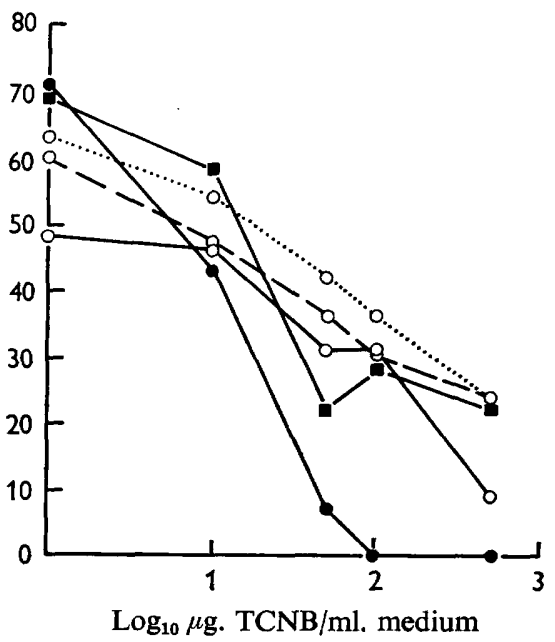

Fig. 2

Fig. I. Aspergillus nidulans: diameters of colonies of wild type (sensitive) and pcnb $\mathrm{I}, p_{c n b}$, $p c n b_{3}$ and $t c n b_{1}$; bi I (resistant) after incubation for 6 days at $37^{\circ}$ on complete medium containing $0-500 \mu \mathrm{g}$. pentachloronitrobenzene (PCNB)/ml. (means of four replicates).

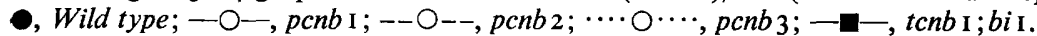

Fig. 2. Aspergillus nidulans: diameters of colonies of wild type (sensitive) and pcnb $\mathrm{I}, p c n b 2$, $p c n b_{3}$ and $t c n b \mathrm{I}_{1} ; b i \mathrm{I}$ (resistant) after incubation at $37^{\circ}$ for 6 days on complete medium containing o-500 $\mu \mathrm{g} .2,3,5,6$-tetrachloronitrobenzene (TCNB) $/ \mathrm{ml}$. (means of four replicates).

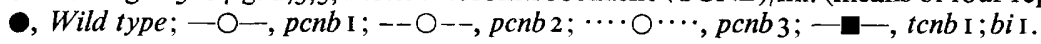

allii resistant to chloronitrobenzenes were also resistant to 2,6-dichloronitroaniline (DCNA). Aspergillus nidulans was insensitive to DCNA; no difference in sensitivity of sensitive and chloronitrobenzene-resistant strains was shown at $0.25 \mathrm{mg}$. DCNA/ml. At this concentration the medium was bright yellow, but surrounding each colony there was a bleached border, suggesting that the compound may have been destroyed. Georgopoulos \& Vomvoyianni (I965) noted that mutants of Hypomyces solani $\mathrm{f}$. cucurbitae resistant to PCNB and TCNB were also resistant to diphenyl. With $A$. nidulans all the chloronitrobenzene-resistant mutants were able to grow on media containing $0.05 \mathrm{mg}$. diphenyl $/ \mathrm{ml}$. Under these conditions the wild type sensitive strain could not grow. Conidiation of strains $p c n b \mathrm{I}$ and $p c n b_{3}$ was unchanged but that of $p_{c n b} 2$ and $t c n b_{1}$ was diminished. All the resistant strains were able to grow and conidiate normally on $\mathrm{CM}$ agar containing $0.05 \mathrm{mg}$. methylene blue or brilliant cresyl $/ \mathrm{ml}$., whereas the wild-type strain grew poorly and did not produce conidia. 


\section{Genetics of chloronitrobenzene resistance}

A prototrophic diploid of Aspergillus nidulans was selected from a stable heterokaryon between pro I $y$; Acr I ; pcnb I and su I ad 20 yad 20; Acr I ; phen 2;pyro 4;lys 5;s 3; nic 8; ribo 2. Loopfuls of diploid conidia were stabbed into plates of CM agar at five equidistant points and $\mathrm{I} \cdot 0 \mathrm{mg}$. PCNB added to the lid. After incubation for 3 days, fast-growing sectors appeared from the stunted colonies. The sectors were either dull yellow (diploid) or bright yellow (haploid) and about equally frequent. One sector was picked from each colony and analysed genetically. All the haploids were

Table 2. Aspergillus nidulans: crosses between chloronitrobenzene-resistant strains

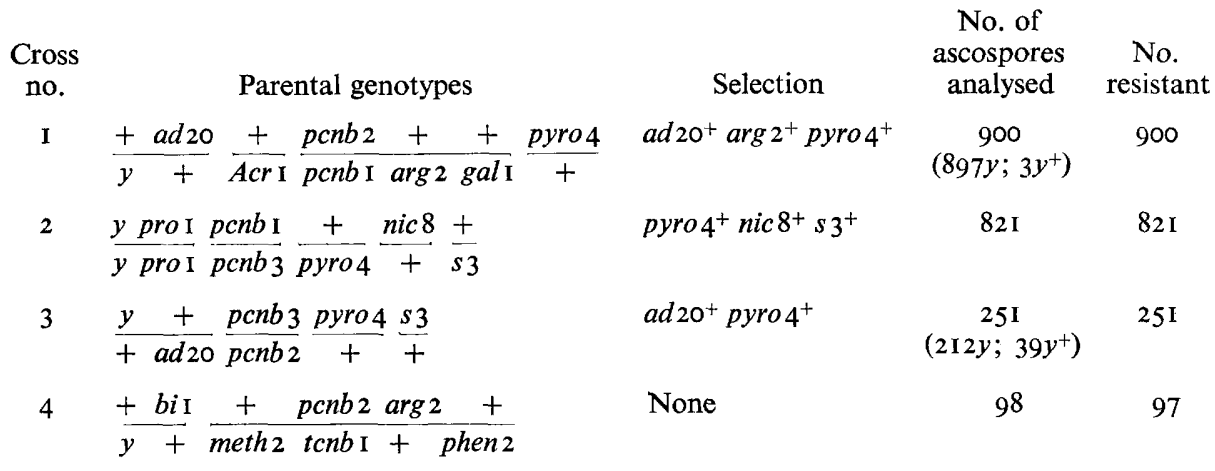

Table 3. Aspergillus nidulans: crosses of chloronitrobenzene strains to bi I arg 2

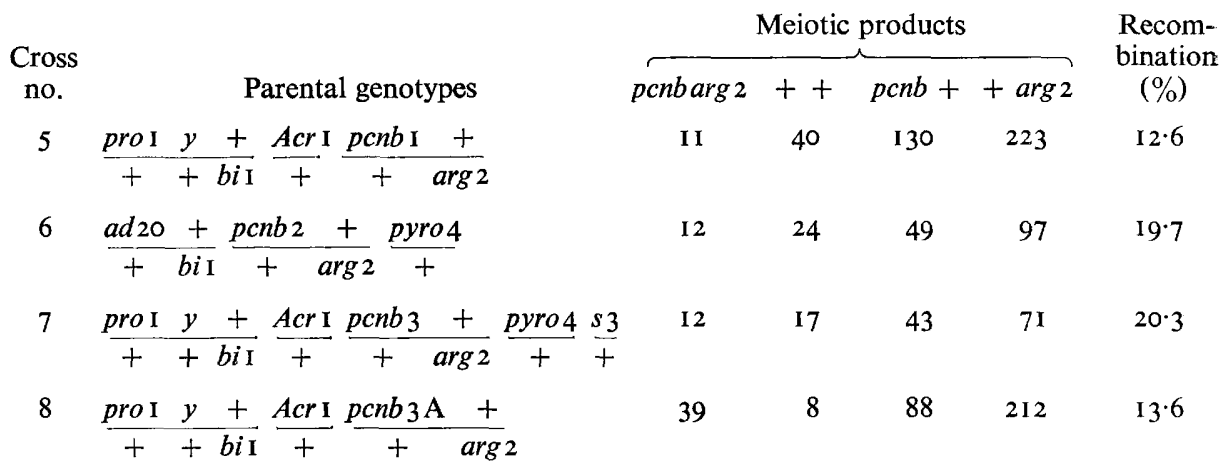

phen $^{+}$but showed assortment of the other heterozygous markers. Thus $p c n b \mathrm{I}$ is located in linkage group III; $p c n b_{3}$ and $t c n b_{I}$ were also located on this chromosome by the same method. Attempts to measure the growth rate of diploids heterozygous for resistance in the presence of PCNB failed because fast-growing sectors appeared sooner or later. However the sensitivity of heterozygous diploids indicated that resistance behaved as a recessive character. Table 2 shows that in crosses between resistant mutants $p c n b_{1}, p c n b_{2}$ and $p c n b_{3}$ there were no sensitive recombinants among the several hundred analysed; this suggests that the three genes are either closely linked or alleles. In a cross between $p c n b 2$ and $t c n b$ I (cross no. 4) one sensitive recombinant $y$ was found in 98 analysed, so these genes may be distinct. Table 3 
shows that the pcnb locus is linked to $\arg 2$ but the frequency of resistant ascospores is less than half so that the marker is unsuitable for use in meiotic analysis. A threepoint cross was made between bi $\mathrm{I} ; t_{c n b} \mathrm{I}$ and $y$; meth 2 gal $\mathrm{I} ;$ nic $8 ;$ ribo 2 . Of 108 ascospores analysed 79 ( $15+64)$ were non-crossovers. There were II $(6+5)$ crossovers between meth 2 and $t c n b \mathrm{I}, \mathrm{I} 7(3+\mathrm{I} 4)$ between $t c n b \mathrm{I}$ and $\arg 2$, and I $(\mathrm{I}+0)$ with crossing-over in both regions. (Figures in parentheses refer to number of resistant and sensitive ascospores respectively.) The results indicate that $t c n b_{\mathrm{I}}$ is situated between meth 2 and gal I. A diploid heterozygous for $p c n b 2$ and $\arg 2$ in coupling was exposed to $\mathrm{PCNB}$ and of $\mathrm{I} 8$ resistant diploid recombinants all required arginine, suggesting that they are homozygous for $\arg 2$ and indicating that the gene for resistance is between $\arg 2$ and the centromere. Slow-growing resistant strains occasionally gave faster-growing sectors which retained the resistance of the parent. The possibility that this was due to mutations taking place elsewhere in the resistance cistron or elsewhere in the genome has not been explored.

\section{The mechanism of chloronitrobenzene action and the nature of resistance}

The chloronitrobenzenes are almost insoluble in water (PCNB I. $5 \mu$ mole/1.) but may accumulate in the biophase and act as toxicants in a non-specific way. Any change which decreased uptake might confer some degree of tolerance on the fungus. That there were differences of this sort was shown by the following experiment. A sensitive (wild type) and resistant ( $p c n b \mathrm{I}$ ) strain of Aspergillus nidulans were grown in liquid $\mathrm{CM}$ for 3 days and then $10 \mathrm{mg}$. TCNB added to each flask. After incubation for a further 3 days the mycelium was collected, washed, dried, weighed and extracted for $24 \mathrm{hr}$ with acetone at $4^{\circ}$. The TCNB in the extracts was then estimated. Table 4 shows that more than five times as much TCNB was extracted from the sensitive mycelium as from the resistant mycelium.

Cytological examination of hyphae produced by conidia incubated overnight in an atmosphere of PCNB showed striking differences between sensitive and resistant strains. Sensitive strains developed short much-branched hyphae with many crosswalls. The cells had thick walls and were crowded with nuclei. Under the same conditions conidia of resistant mutants gave long thin hyphae with few cross-walls and few nuclei per cell, and were indistinguishable from hyphae of either strain grown in the absence of PCNB. These effects were studied quantitatively on cultures grown in liquid $\mathrm{MM}$ containing $0 . \mathrm{I} \mathrm{mg}$. PCNB $/ \mathrm{ml}$. Table 5 shows that PCNB depressed growth more than DNA synthesis in the sensitive strain, so that the DNA content was increased. There was no significant effect of PCNB on the resistant strain. Even in the absence of the fungistat the sensitive strain utilized glucose at a rate lower than did the resistant strain. There were no significant differences between the inorganic phosphate content of culture filtrates. When this experiment was repeated with $0 . \mathrm{I} \mathrm{mg}$. TCNB $/ \mathrm{ml}$. the results shown in Table 6 were obtained. No values for the sensitive strain with TCNB are given because no growth was made. These experiments show that PCNB did not inhibit mitosis as suggested by Horsfall (I956) although TCNB may do so.

PCNB and TCNB may release nascent chlorine which could act as an oxidizing agent and/or produce an antimetabolite by causing chlorination of a metabolite (Rich, 1960). Chloramine $\mathrm{T}$ is known to act in this way but there was no difference between sensitive and resistant strains in their response to this chemical. Rich (I960) 
also suggested that chloronitrobenzenes might be competitive inhibitors of inositol synthesis. Addition of $0.05^{-0.50} \mathrm{mg}$. inositol $/ \mathrm{ml}$. had no effect on the growth of sensitive strains in the presence of PCNB.

Table 4. Aspergillus nidulans: tetrachloronitrobenzene content of resistant and sensitive strains

$\begin{array}{lcc} & \text { Dry wt. mycelium } & \mu \mathrm{g} \text {. TCNB/mg. } \\ \text { Strain (genotype) } & (\mathrm{mg} .) & \text { mycelium } \\ \text { Sensitive (wild type) } & 98.9 & 35.4 \\ \text { Resistant (pcnb I) } & 268.5 & 6.5\end{array}$

Each value is the mean of five replicate cultures.

Table 5. Aspergillus nidulans: effect of $0 \cdot 1 \mathrm{mg}$. PCNB/ml. on mycelium dry weight, $D N A$ content and glucose uptake of sensitive and resistant strains

\begin{tabular}{|c|c|c|c|c|c|}
\hline Strain & Treatment & $\begin{array}{l}\text { Mycelium } \\
\text { dry wt. } \\
\text { (mg.) }\end{array}$ & $\begin{array}{l}\text { Total } \\
\text { DNA } \\
(\mu \mathrm{g} .)\end{array}$ & $\begin{array}{c}\text { DNA } \\
(\mu \mathrm{g} . / 100 \mathrm{mg} . \\
\text { dry } \\
\text { mycelium) }\end{array}$ & $\begin{array}{l}\text { Glucose } \\
(\mu \mathrm{g} . / \mathrm{ml} \text {. } \\
\text { culture } \\
\text { filtrate })\end{array}$ \\
\hline Sensitive (wild type) & $\begin{array}{l}\text { PCNB } \\
\text { Control }\end{array}$ & $\begin{array}{r}69 \\
\times 51\end{array}$ & $\begin{array}{l}247 \\
324\end{array}$ & $\begin{array}{l}362 \\
216\end{array}$ & $\begin{array}{l}6800 \\
2740\end{array}$ \\
\hline Resistant ( $\left.p c n b_{3}\right)$ & $\begin{array}{l}\text { PCNB } \\
\text { Control }\end{array}$ & $\begin{array}{l}145 \\
162\end{array}$ & $\begin{array}{l}336 \\
324\end{array}$ & $\begin{array}{l}232 \\
230\end{array}$ & $\begin{array}{r}17 \\
123\end{array}$ \\
\hline
\end{tabular}

Each figure is the mean of five replicate cultures.

Table 6. Aspergillus nidulans: Effect of $0.1 \mathrm{mg} . \mathrm{TCNB} / \mathrm{ml}$. on mycelium dry weight $D N A$ content and glucose uptake of sensitive and resistant strains

\begin{tabular}{|c|c|c|c|c|c|}
\hline Strain & Treatment & $\begin{array}{l}\text { Mycelium } \\
\text { dry wt. } \\
\text { (mg.) }\end{array}$ & $\begin{array}{l}\text { Total } \\
\text { DNA } \\
(\mu \mathrm{g} .)\end{array}$ & $\begin{array}{c}\text { DNA } \\
(\mu \mathrm{g} . / 100 \mathrm{mg} . \\
\text { dry } \\
\text { mycelium) }\end{array}$ & $\begin{array}{l}\text { Glucose } \\
(\mu \mathrm{g} . / \mathrm{ml} . \\
\text { culture } \\
\text { filtrate })\end{array}$ \\
\hline \multirow{2}{*}{ 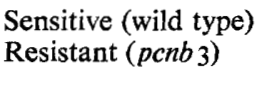 } & $\begin{array}{l}\text { Control } \\
\text { TCNB }\end{array}$ & $\begin{array}{r}119 \\
18\end{array}$ & $\begin{array}{l}701 \\
232\end{array}$ & $\begin{array}{r}477 \\
1329\end{array}$ & $\begin{array}{r}3090 \\
10400\end{array}$ \\
\hline & Control & I36 & 698 & 515 & 520 \\
\hline
\end{tabular}

Each figure is the mean of five cultures.

If PCNB or TCNB act as uncouplers of oxidative phosphorylation respiration would be stimulated, and the loss of energy by failure of ATP synthesis might be enough to retard growth. No change in the respiration rate of sensitive or resistant strains was detected over a period of $2 \mathrm{hr}$ after the addition of $0.125 \mathrm{mg}$. PCNB or $\mathrm{TCNB} / \mathrm{ml}$.

PCNB and TCNB might increase cell permeability so that loss of low molecular weight substances limited growth, but no differences in the amino acid content of culture filtrates from sensitive or resistant cultures was detected $\mathrm{I}$ or 6 days after the addition of PCNB to cultures to give a concentration of $0.4 \mathrm{mg} . / \mathrm{ml}$. 


\section{DISCUSSION}

Resistant mutants of Aspergillus nidulans, which appear to arise more frequently in the presence of PCNB than with TCNB, are mutant for a gene in linkage group III. One gene may be responsible or two closely linked genes. Those resistant mutants selected by PCNB are allelic but have different growth rates and sensitivities to other chemicals. The production of homozygous resistant diploid segregants by sensitive heterozygous diploids to PCNB should provide a method for mapping genes on this arm of the chromosome by mitotic recombination. The cause of toxicity has not been discovered; inhibition of inositol metabolism or evolution of nascent chlorine appear unlikely to explain the fungistatic action of PCNB or TCNB.

Lehninger (I949) showed that when methylene blue or brilliant cresyl green substitutes for the cytochrome system in electron transport there is an uncoupling of ATP synthesis. The resistance to the dyes shown by PCNB- and TCNB-resistant mutants may indicate that these compounds also act in this fashion. However, they may act quite differently inside the cell but share the same path for uptake or entry. If this path is blocked in a mutant strain then resistance will be shown to all those compounds that use it. This line of argument can account for resistance to other halogenated nitrobenzenes and to diphenyl.

The high content of TCNB extracted from a sensitive strain of Aspergillus nidulans as compared with a resistant strain may reflect either the inability of the resistant strain to accumulate TCNB or its ability to inactivate it. The fate of halogenated nitrobenzenes in vivo has been studied in the rat and rabbit but not in fungi. The labile nitro group of PCNB and TCNB is replaced by a cysteinyl group with the formation of a mercapturic acid (Bray, Hybs, James \& Thorpe, I953); cysteine required for this synthesis is derived from glutathione by a specific enzyme glutathiokinase (Al-Kassab, Boyland \& Williams, 1962; Booth, Boyland \& Sims, 196I). Georgopoulos \& Vomvoyianni (1965) looked for this enzyme in PCNB-resistant mutants of Hypomyces solani f. cucurbitae without success. They pointed out that if it had been present it could not have accounted for resistance to diphenyl. Resistance would therefore seem to result from a decreased ability to accumulate the toxic chemical rather than from an ability to metabolize it to some harmless product. A. nidulans is more sensitive to TCNB than PCNB; Botrytis cinerea behaves in this way (Reavill, I954), whereas the reverse is true for Rhizoctania solani (Brown \& Montgomery, 1948). Both compounds are virtually inactive against Pythium and Phytophthora (Reavill, I954). These variations in sensitivity may indicate differences in the nature or organization of the hyphal wall.

\section{REFERENCES}

Al-Kassab, S., Boyland, E. \& Williams, K. (I962). The replacement of aromatic nitro groups with glutathione by glutathiokinase of rat liver. Biochem. $J .83, \mathrm{I} 2$.

APIRION, D. (1962). A general system for the automatic selection of auxotrophs from prototrophs and vice versa in micro-organisms. Nature, Lond. 195, 959.

Auerbach, M. E. (1950). The colorimetric estimation of tetrachloronitrobenzene. Analyt. Chem. 22, 1287.

BoоTH, J., BoYland, E. \& Sims, P. (196I). An enzyme from rat liver catalysing conjugations with glutathione. Biochem. J. 79, 516. 
Bray, H. G., Hybs, Z., James, S. P. \& Thorpe, W. V. (I953). The metabolism of 2:3:5:6- and $2: 3: 4: 5$-tetrachloronitrobenzene in the rabbit and the reduction of aromatic nitrocompounds in the intestine. Biochem. J. 53, 266.

Brown, W. \& Montgomery, N. (1948). Problems in the cultivation of winter lettuce. Ann. appl. Biol. 35, 161.

Burton, K. (I956). A study of the conditions and mechanism of diphenylamine reaction for the colorimetric estimation of deoxyribonucleic acid. Biochem. J. 62, 315.

DAHLQvisT, A. (196I). Determination of maltase and isomaltase activities with a glucose-oxidase reagent. Biochem. $J .80,547$.

Fiske, C. H. \& SubbaRow, Y. (1925). The colorimetric determination of phosphorus. J. biol. Chem. 66,375 .

Georgopoulos, S. G. (1963). Tolerance to chlorinated nitrobenzenes in Hypomyces solani f. cucurbitae and its mode of inheritance. Phytopathology 53, 1086.

Georgopoulos, S. G. \& Vomvoyianni, V. E. (1965). Differential sensitivity of diphenyl-sensitive and diphenyl-tolerant strains of fungi to chlorinated nitrobenzenes and to some diphenyl derivatives. Canad. J. Bot. 43, 765 .

Horsfall, J. G. (1956). Principles of Fungicidal Action. Waltham, Mass.: Chronica Botanica.

KäFER, E. (1958). An 8-chromosome map of Aspergillus nidulans. Advanc. Genet. 9, 105.

LEHNINGER, A. L. (I949). Esterification of inorganic phosphate coupled to electron transport between dihydrodiphosphopyridine nucleotide and oxygen. II. J. biol. Chem. 178, 625 .

MCKEE, R. K. (195I). Mutations appearing in Fusarium caeruleum cultures treated with tetrachloronitrobenzene. Nature, Lond. x67, 6I I.

Moore, S. \& SteIN, W. H. (I948). Photometric ninhydrin method for use in the chromatography of amino acids. J. biol. Chem. 176, 367.

Pontecorvo, G., Roper, J. A., Hemmons, L. M., Macdonald, K. D. \& Bufton, A. W. J. (i953). The genetics of Aspergillus nidulans. Advanc. Genet. 5, I4I.

Priest, D. \& Wood, R. K. S. (I96I). Strains of Botrytis allii resistant to chlorinated nitrobenzenes. Ann. appl. Biol. 49, 445.

Reavill, M. J. (I 954). Effect of certain chloronitrobenzenes on germination, growth and sporulation of some fungi. Ann. appl. Biol. 4r, 448 .

RICH, S. (1960). Fungicidal chemistry. In Plant Pathology, vol. 2. New York: Academic Press.

RoBerts, C. F. (1963). The genetic analysis of carbohydrate utilization in Aspergillus nidulans. J. gen. Microbiol. 3r, 45 .

ROPER, J. A. \& KÄFER, E. (1957). Acriflavine-resistant mutants of Aspergillus nidulans. J. gen. Microbiol. $16,660$.

WARR, J. R. \& ROPER, J. A. (1965). Resistance to various inhibitors in Aspergillus nidulans. J. gen. Microbiol. 40, 273. 